\title{
Pengaruh Keaktifan Siswa Dalam Kegiatan Ekstrakurikuler Multimedia Club (M2C) Terhadap Prestasi Belajar Siswa Dalam Mata Pelajaran Komposisi Foto Digital Kelas XI Multimedia SMK Negeri 2 Jakarta
}

\author{
Regina Arzica Pranata, Ivan Hanafi \\ Pendidikan Teknik Informatika dan Komputer \\ Universitas Negeri Jakarta \\ reginaarzica@gmail.com, ivan.hanafi@unj.ac.id
}

\begin{abstract}
Abstrak
Penelitian ini bertujuan untuk mengetahui pengaruh keaktifan siswa dalam kegiatan ekstrakurikuler Multimedia Club terhadap prestasi belajar siswa dalam mata pelajaran komposisi foto digital kelas XI Miltimedia SMK Negeri 2 Jakarta tahun ajaran 2014/2015. Penelitian ini merupakan penelitian kuantitatif dengan mengambil sampel 20 siswa kelas XI Multimedia SMK Negeri 2 Jakarta yang mengikuti kegiatan ekstrakurikuler multimedia club. Data tentang keaktifan siswa dalam kegiatan ekstrakurikuler Multimedia Club pada penelitian ini diambil dengan instrumen angket tertutup, sedangkan untuk data prestasi belajar diambil dengan menggunakan metode dokumentasi, yaitu dengan nilai rapor siswa.

Hasil dari pengujian hipotesis pada pengujian pertama menunjukan bahwa terdapat pengaruh yang positif dan signifikan antara pengaruh keaktifan siswa dalam kegiatan ekstrakurikuler Multimedia Club terhadap prestasi belajar siswa ranah pengetahuan dalam mata pelajaran komposisi foto digital dengan korelasi product moment menghasilkan $r_{\text {hitung }}$ sebesar 0,570 dengan $r_{\text {tabel }}$ pada tabel signifikansi 5\% sebesar 0,44 sehingga harga $r_{\text {hitung }}>r_{\text {tabel }}$. Dibuktikan pula dengan persamaan regresi $Y^{\prime}=61,55+0,213 X$, menunjukan bahwa penerapan keaktifan siswa dalam kegiatan ekstrakurikuler Multimedia Club bertambah satu, maka prestasi belajar siswa ranah pengetahuan dalam mata pelajaran komposisi foto digital bertambah 0,213 Nilai koefisien determinasi sebesar 32,47 yang berarti sumbangan pengaruh keaktifan siswa dalam kegiatan ekstrakurikuler Multimedia Club terhadap prestasi belajar siswa ranah pengetahuan dalam mata pelajaran komposisi foto digital adalah sebesar 32,47\%, sedangkan 67,53\% ditentukan oleh faktor lain.

Sedangkan pada pengujian kedua menunjukan bahwa terdapat pengaruh yang positif dan signifikan antara pengaruh keaktifan siswa dalam kegiatan ekstrakurikuler Multimedia Club terhadap prestasi belajar siswa ranah keterampilan dalam mata pelajaran komposisi foto digital dengan korelasi product moment menghasilkan $r_{\text {hitung }}$ sebesar 0,571 dengan $r_{\text {tabel }}$ pada tabel signifikansi 5\% sebesar 0,44 sehingga harga $r_{\text {hitung }}>$ $r_{\text {tabel. }}$ Dibuktikan pula dengan persamaan regresi $Y^{\prime}=67,48+0,136$ X. Nilai koefisien determinasi sebesar 32,55 yang berarti sumbangan pengaruh keaktifan siswa dalam kegiatan ekstrakurikuler Multimedia Club terhadap prestasi belajar siswa ranah keterampilan dalam mata pelajaran komposisi foto digital adalah sebesar 32,55\%, sedangkan $67,45 \%$ ditentukan oleh faktor lain.
\end{abstract}

Kata kunci : Ektrakurikuler, Multimedia Club, Prestasi belajar, Komposisi foto digital

\section{Pendahuluan}

Latar Belakang

SMK Negeri 2 Jakarta merupakan salah satu instansi pendidikan formal yang memegang peranan penting dalam mencetak generasi penerus yang berkualitas. Berdasarkan hasil observasi yang telah dilakukan selama Praktek Keterampilan Mengajar di SMK Negeri 2 Jakarta diketahui bahwa sekolah ini sedang mengalami renovasi bangunan sejak Juli tahun 2013.
Mata pelajaran komposisi foto digital di memiliki alokasi waktu 4 jam pelajaran atau setara dengan 4 x 45 menit perminggu. Akibat renovasi sekolah, mata pelajaran ini juga mengalami pengurangan jam pelajaran menjadi 4 x 30 menit. Maka dari itu peserta didik mengalami kekurangan jam pelajaran di kelas sebanyak 60 menit. Ini mengakibatkan peserta didik kurang dalam mendalami materi.

Untuk mencapai prestasi belajar yang optimal peserta didik tidak cukup diberikan materi 
pelajaran yang terdapat dalam materi kurikulum yang ada dan berlaku di sekolah, melainkan juga perlu adanya kegiatan-kegiatan tambahan di luar pelajaran. Salah satu wadah pembinaan siswa di sekolah adalah kegiatan ekstrakurikuler.

Melalui kegiatan ekstrakurikuler siswa dapat bertambah wawasan mengenai mata pelajaran yang erat kaitannya dengan pelajaran di ruang kelas dan biasanya yang membimbing siswa dalam mengikuti kegiatan ekstrakurikuler adalah guru bidang studi yang bersangkutan.

\section{Tujuan Penelitian}

1. Mengetahui pengaruh keaktifan siswa dalam kegiatan ekstrakurikuler Multimedia Club terhadap prestasi belajar siswa dalam mata pelajaran komposisi foto digital kelas XI Multimedia SMK Negeri 2 Jakarta.

2. Mengetahui seberapa besar pengaruh keaktifan siswa dalam kegiatan ekstrakurikuler Multimedia $C l u b$ terhadap prestasi belajar siswa dalam mata pelajaran komposisi foto digital kelas XI Multimedia SMK Negeri 2 Jakarta.

\section{Dasar Teori}

\section{Prestasi Belajar}

Prestasi belajar adalah hasil pengukuran dari penilaian usaha belajar yang dinyatakan dalam bentuk simbol, angka, huruf maupun kalimat yang menceritakan hasil yang sudah dicapai oleh setiap anak pada periode tertentu. Prestasi belajar merupakan hasil dari pengukuran terhadap peserta didik yang meliputi faktor kognitif, afektif dan psikomotor setelah mengikuti proses pembelajaran yang diukur dengan menggunakan instrumen tes yang relevan.

Prestasi belajar menurut Benyamin Bloom secara garis besar dibagi tiga ranah, yaitu kognitif, ranah afektif, ranah psikomotor. Ranah kognitif berkenaan dengan hasil belajar intelektual. Ranah afektif berkenaan dengan sikap dan nilai. Ranah psikomotorik erat sekali dengan keterampilan yang bersifat konkret, walaupun demikian tidak terlepas dari kegiatan belajar yang bersifat mental (pengetahuan dan sikap).

Faktor-faktor yang mempengaruhi proses dan prestasi belajar

Muhibbin Syah dalam bukuya Psikologi Pendidikan merinci faktor-faktor tersebut adalah sebagai berikut.

Tabel 2.1 Faktor-faktor yang mempengaruhi proses dan prestasi belajar

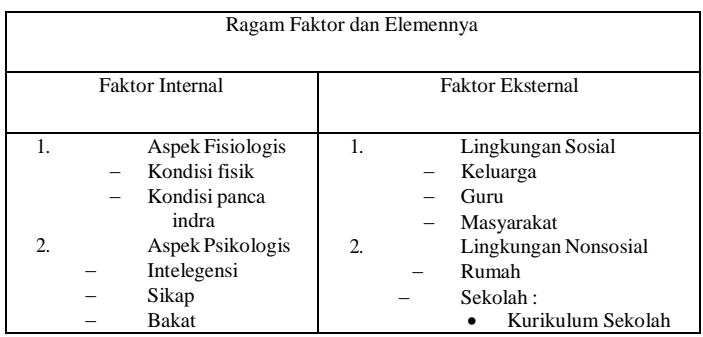

\begin{tabular}{|llll|}
\hline- & Minat & $\bullet$ & Sarana prasarana \\
- & Motivasi & & sekolah \\
& & & Kegiatan penunjang \\
& & \\
\hline
\end{tabular}

\section{Mata Pelajaran Komposisi Foto Digital}

Mata pelajaran komposisi foto digital pada kurikulum 2013 merupakan salah satu bagian dari kelompok mata pelajaran produktif pada program studi keahlian multimedia yang diberikan pada kelas XI.

Mata pelajaran komposisi foto digital memiliki alokasi waktu 4 jam pelajaran tiap minggu. Ektrakurikuler Multimedia Club

Ekstrakurikuler Multimedia Club adalah suatu kegiatan yang dilakukan diluar jam pelajaran yang dilaksanakan disekolah maupun luar sekolah dengan maksud untuk mengembangkan bidang multimedia khususnya fotografi. Ekstrakurikuler Multimedia Club pertama kali di gagas oleh salah satu guru mata pelajaran produktif di SMK 2 Jakarta beserta beberapa siswa/siswi pada tahun 2010 .

Tujuan awal dari ekstrakurikuler ini adalah memberikan wadah untuk siswa/siswi untuk menyalurkan bakat, minat, kemampuannya serta menambah wawasan dan pengetahuan mengenai bidang multimedia.

\section{Keaktifan}

Keaktifan adalah suatu kegiatan/aktifitas atau segala sesuatu yang dilakukan atau kegiatankegiatan yang terjadi baik fisik maupun non fisik

\section{Metodologi}

\section{Jenis dan desain Penelitian.}

Jenis dan desain penelitian adalah Kuantitatif dengan teknik analisa bersifat deskriptif korelasional.

\section{Populasi dan Sampel}

Populasi yang diambil adalah seluruh anggota ekstrakurikuler multimedia club tahuan ajaran 20142015 yang terdiri dari siswa kelas X dan XI Multimedia SMK Negeri 2 Jakarta sejumlah 36 siswa.Sampel dalam penelitian ini ditentukan dengan menggunakan teknik Sampling Purposive

Sampel yang diambil adalah siswa kelas XI Multimedia yang mengikuti kegiatan tan ekstrakurikuler Multimedia Club yaitu berjumlah 20 siswa.

\section{Teknik Pengumpulan Data}

Untuk memperoleh data-data yang diperlukan dalam penelitian ini digunakan berbagai metode antara lain:

1.Wawancara, Wawancara dilakukan dalam bentuk dialog langsung dengan pembina, pembimbing dan ketua ekstrakurikuler multimedia club

2.Dokumentasi, adalah adalah mencari data mengenai hal-hal atau variabel yang berupa catatan, transkrip, buku, surat kabar, majalah, prasasti, nilai rapor dan sebagainya.

3.Kuesioner, merupakan metode untuk memperoleh data dengan cara memberikan pertanyaan yang 
disusun dalam suatu daftar yang dijawab oleh subyek penelitian.

Teknik Analisis Data dan Pengujian Hipotesis

1. Analisis Deskriptif Persentase

2. Uji Normalitas, Menggunakan uji lilliefors :

$\mathrm{L}_{0}=|f(Z i)-S(Z i)|$

3. Uji Validitas dan Uji Relibilitas

Uji validitas dengan pendapat para ahli. Uji

reliabilitas menggunakan rumus alpha cronbach.

4. Pengujian hipotesis

Untuk mengetahui ada tidaknya hubungan antara kedua variabel digunakan.

(1) Uji keberartian regresi

F.hitung=

$$
\frac{J K(b / a)}{1}
$$

Jika $\mathrm{F}_{\text {hitung }}>\mathrm{F}_{\text {tabe }} \mathrm{l}, \mathrm{H}_{0}$ ditolak, dan regresi dinyatakan berarti ( signifikan )

(2) Uji Lineritas regresi F.hitung

$$
\frac{s^{2} T C}{S^{2} G}
$$

(3)

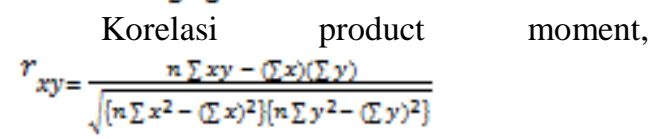

(4) Uji keberartian koefisien korelasi

T.hitung $=\frac{r \sqrt{n-2}}{\sqrt{1-(r)^{2}}}$

Ho ditolak bila $t_{\text {hitung }}<t_{\text {tabel }}$, maka korelasi berarti (signifikan).

(5) Koefisien Determinasi

$\mathrm{KD}=\mathrm{r}_{\mathrm{xy}} \times 100 \%$

\section{Hasil dan Analisis \\ Uji Normalitas,}

Variabel X

(Keaktifan dalam

Ekstrakurikuler Multimedia $\mathrm{Club}$ ). Dari Perhitungan nilai $\mathrm{L}_{\text {hitung }}$ terbesar $0,125, \mathrm{~L}_{\text {tabel }}$ untuk $\mathrm{n}=20$ dengan taraf signifikan 0,05 adalah $0,190 . \mathrm{L}_{\text {hitung }}<\mathrm{L}_{\text {tabel }}$. Dengan demikian dapat disimpulkan data berdistribusi Normal.

Variabel $\mathrm{Y}_{1}$ (Prestasi Belajar Ranah Pengetahuan)Dari Perhitungan nilai $\mathrm{L}_{\text {hitung }}$ terbesar 0,125 , L tabel untuk $\mathrm{n}=20$ dengan taraf signifikan 0,05 adalah 0,190. $\mathrm{L}_{\text {hitung }}<\mathrm{L}_{\text {tabel }}$. Dengan demikian dapat disimpulkan data berdistribusi Normal.

Variabel $\mathrm{Y}_{2} \quad$ (Prestasi Belajar Ranah Keterampilan)Dari Perhitungan nilai $\mathrm{L}_{\text {hitung }}$ terbesar $0,108, \mathrm{~L}_{\text {tabel }}$ untuk $\mathrm{n}=20$ dengan taraf signifikan 0,05 adalah 0,190. $\mathrm{L}_{\text {hitung }}<\mathrm{L}_{\text {tabel. }}$. Dengan demikian dapat disimpulkan data berdistribusi Normal

\section{Uji Validitas dan Uji Relibilitas}

Hasil uji validitas dari 41 dinyatakan valid sebanyak 37 pernyataan dan tidak valid sebanyak 4 pernyataan. Hasil uji reliabilitas menyatakan bahwa instrumen reliabel untuk digunakan dalam penelitian dengan rhitung $=0,976$ maka termasuk kedalam kategori reliabel sangat tinggi.

\section{Uji keberartian regresi}

Hasil perhitungan uji keberartian regresi pada perhitungan Keaktifan siswa dengan prestasi belajar ranah pengetahuan menunjukan nilai $F_{\text {hitung }}$ sebesar 8,66 dan nilai $F_{\text {tabel }}(0,05 ; 1 / 18)=4,41$. Berdasarkan hasil tersebut maka hipotesis Ho ditolak, karena $F_{\text {hitung }}>F_{\text {tabel,sehingga dapat }}$ disimpulkan bahwa arah persamaan regresi adalah signifikan.

Hasil perhitungan uji keberartian regresi pada perhitungan Keaktifan siswa dengan prestasi belajar ranah keterampilan menunjukan nilai $\mathrm{F}_{\text {hitung }}$ sebesar 8,69 dan nilai $F_{\text {tabel }}(0,05 ; 1 / 18)=4,41$. Berdasarkan hasil tersebut maka hipotesis Ho ditolak, karena $F_{\text {hitung }}>F_{\text {tabel,sehingga dapat }}$ disimpulkan bahwa arah persamaan regresi adalah signifikan.

\section{Uji Lineritas regresi}

Hasil perhitungan uji lineritas regresi pada perhitungan Keaktifan siswa dengan prestasi belajar ranah pengetahuan menunjukan nilai Fhitung 0,23 dan Ftabel $(0,05 ; 15 / 3)=8,71$, maka hipotesis Ho diterima sebab Fhitung < Ftabel. Sehingga model persamaan regresi adalah Linear dalah signifikan.

Hasil perhitungan uji lineritas regresi pada perhitungan Keaktifan siswa dengan prestasi belajar ranah keterampilan menunjukan nilai Fhitung 0,32 dan Ftabel $(0,05 ; 15 / 3)=8,71$, maka hipotesis Ho diterima sebab Fhitung < Ftabel. Sehingga model persamaan regresi adalah Linear dalah signifikan.

\section{Korelasi product moment,}

Pada perhitungan product moment Keaktifan siswa dengan prestasi belajar ranah pengetahuan diperoleh $\mathrm{r}_{\text {hitung }}\left(\mathrm{r}_{\mathrm{xy}}\right)=0,570$. Dengan mengacu kepada Interpretasi Angka Indeks Korelasi "r"Product Moment dapat disimpulkan bahwa terdapat hubungan yang positif antara variabel $\mathrm{X}$ terhadap variabel $Y_{1}$ yang sedang atau cukup.

Pada perhitungan product moment Keaktifan siswa dengan prestasi belajar ranah keterampilan diperoleh $\mathrm{r}_{\text {hitung }}\left(\mathrm{r}_{\mathrm{xy}}\right)=0,571$. Dapat disimpulkan bahwa terdapat hubungan yang positif antara variabel $\mathrm{X}$ terhadap variabel $\mathrm{Y}_{2}$ yang sedang atau cukup.

\section{Uji keberartian koefisien korelasi}

PadaKeaktifan siswa dengan prestasi belajar ranah pengetahuan diperoleh thitung $=2,94$ dan ttabel pada taraf signifikan 0,05 dan $\mathrm{dk}(\mathrm{n}-2)=$ 18 adalah 1,73. Demikian thitung > ttabel $(2,94>$ 0,44) maka Ho ditolak. Sehingga dari perhitungan uji $\mathrm{t}$ menyatakan terdapat hubungan positif yang signifikan antara $\mathrm{X}$ terhadap variabel prestasi belajar ranah pengetahuan

PadaKeaktifan siswa dengan prestasi belajar ranah keterampilan diperoleh thitung $=2,95$ dan ttabel pada taraf signifikan 0,05 dan $\mathrm{dk}(\mathrm{n}-2)=$ 18 adalah 1,73. Demikian thitung > ttabel $(2,95>$ $0,44)$ maka Ho ditolak. Sehingga dari perhitungan 
uji t menyatakan terdapat hubungan positif yang signifikan antara $\mathrm{X}$ terhadap variabel prestasi belajar ranah keterampilan

\section{Koefisien Determinasi}

PadaKeaktifan siswa dengan prestasi belajar ranah pengetahuan besarnya koefisien determinasi sebesar 32,47 \% variabel Y dijelaskan oleh variabel $\mathrm{X}$.

PadaKeaktifan siswa dengan prestasi belajar ranah keterampilan besarnya koefisien determinasi sebesar 32,55 \% variabel Y dijelaskan oleh variabel $\mathrm{X}$.

\section{Kesimpulan dan Saran}

Kesimpulan

1. Kegiatan ekstrakurikuler multimedia club berpengaruh positif secara signifikan terhadap prestasi belajar siswa pada mata pelajaran komposisi foto digital ranah pengetahuan kelas XI multimedia SMK Negeri 2 Jakarta. Artinya prestasi belajar siswa pada mata pelajaran komposisi foto digital ranah pengetahuan kelas XI multimedia SMK Negeri 2 Jakarta akan meningkat apabila terjadi kenaikan keaktifan pada ekstrakurikuler multimedia club.

2. Kegiatan ekstrakurikuler multimedia club berpengaruh positif secara signifikan terhadap prestasi belajar siswa pada mata pelajaran komposisi foto digital ranah keterampilan kelas XI multimedia SMK Negeri 2 Jakarta. Artinya prestasi belajar siswa pada mata pelajaran komposisi foto digital ranah keterampilan kelas XI multimedia SMK Negeri 2 Jakarta akan meningkat apabila terjadi kenaikan keaktifan pada ekstrakurikuler multimedia club.

3. Pengaruh keaktifan siswa dalam ekstrakurikuler multimedia club dengan prestasi belajar siswa pada mata pelajaran komposisi foto digital kelas ranah pengetahuan XI multimedia berada pada kategori sedang atau cukup.

4. Pengaruh keaktifan siswa dalam ekstrakurikuler multimedia club dengan prestasi belajar siswa pada mata pelajaran komposisi foto digital kelas ranah keterampilan XI multimedia berada pada kategori sedang atau cukup.

\section{Saran}

1. Bagi siswa, meningkatkan prestasi belajar pada mata pelajaran komposisi foto digital kelas XI disarankan untuk berpartisipasi aktif dalam setiap kegiatan ekstrakurikuler multimedia club agar dapat mengembangkan minat dan bakat yang dimiliki serta dapat menambah wawasan siswa.

2. Bagi pihak sekolah diharapkan agar dapat mendukung, memelihara dan memberikan fasilitas yang memadai agar kegiatan ekstrakurikuler dapat berjalan dengan baik dan sesuai dengan rancangan awal.

\section{Daftar Pustaka:}

Ahmadi, Abu. 1991. Sosiologi Pendidikan. Jakarta: Rineke Cipta.

Andi. 2004. 10 Model Penelitian dan Pengolahannya dengan SPSS. Semarang: Wahana Komputer

Arikunto, Suharsimi. 2010. Prosedur Penelitian Suatu Pendekatan Praktik. Jakarta: PT. Rineka Cipta.

Azwar, Saifuddin. 2012. Reliabilitas dan Validitas. Yogyakarta: Pustaka Pelajar.

Departemen Pendidikan dan Kebudayaan. 1985. Petunjuk Teknis Tata Cara

Berorganisasi Siswa. Dirjen Pendidikan Dasar dan Menengah

Direktorat Pembinaan Kesiswaan: Jakarta.

Dimyati, Mudjiono. 2006. Belajar dan Pembelajaran. PT. Rineka Cipta: Jakarta.

Fakultas Teknik. 2012. Buku Pedoman Skripsi/Komprehensif/ Karya Inovatif S1.

Jakarta: Fakultas Teknik Universitas Negeri Jakarta.

Ghozali, Imam. 2006. Aplikasi Analisi Multivariate dengan Program SPSS.

Semarang: Badan Penerbit Universitas Diponegoro.

Hamalik,Oemar.2011. Dasar-dasar Pengembangan Kurikulum. Bandung:

Remaja Rosdakarya.

Hamalik, Oemar. 2009. Kurikulum dan Pembelajaran. Jakarta: Bumi Aksara.

Mulyono. 2009. Management Administrasi \& Organisasi Pendidika. Jakarta:

Ar:Ruzz Media.

Purwanto, M. Ngalim. 2013. Psikologi Pendidikan. Bandung: Remaja

Rosdakarya.

Sudijono, Anas. 2010. Pengantar Statistik Pendidikan. Jakarta : PT RajaGrafindo

Persada.

Sudjana, Nana. 2010. Penelilaian Proses Hasil Belajar Mengajar . Bandung: PT.

Remaja Rosdakarya

Sugiyono. 2013. Metode Penelitian Pendidikan. Bandung: Alfabeta.

Sunarto, 2015. "Pengertian Prestasi Belajar",http://sunartombs.wordpress.com

/2009/01/05/pengertian-prestasi-belajar/. Diakses pada 10 April.

Suryobroto, B. 2009. Proses Belajar Mengajar di Sekolah. PT. Rineka Cipta:

Jakarta.

Syah, Muhibbin. 2010. Psikologi Pendidikan dengan Pendekatan Baru.

Bandung: Remaja Rosdakarya.

Walpole, Ronald E. 1992. Pengantar Statistika. Jakarta: PT. Gramedia Pustaka

Umum.

Z,Zurinal dan Wahdi Sayuti. 2006. Ilmu Pendidikan: Pengantar dan Dasar-dasar

Pelaksanaan Pendidikan. Jakarta:UIN Jakarta Press 